P. Cras · F. van Harskamp • L. Hendriks

C. Ceuterick - C. M. van Duijn - S. Z. Stefanko

A. Hofman · J. M. Kros • C. Van Broeckhoven

J. J. Martin

\title{
Presenile Alzheimer dementia characterized by amyloid angiopathy and large amyloid core type senile plaques in the APP 692Ala $\rightarrow$ Gly mutation
}

Received: 11 August 1997 / Revised, accepted: 9 February 1998

\begin{abstract}
Mutations at codons 717 and 670/671 in the amyloid precursor protein (APP) are rare genetic causes of familial Alzheimer's disease (AD). A mutation at codon 693 of APP has also been described as the genetic defect in hereditary cerebral hemorrhage with amyloidosis of the Dutch type (HCHWA-D). We have reported a APP692Ala $\rightarrow$ Gly (Flemish) mutation as a cause of intracerebral hemorrhage and presenile dementia diagnosed as probable $\mathrm{AD}$ in a Dutch family. We now describe the post-mortem examination of two demented patients with the APP692 mutation. The neuropathological findings support the diagnosis of AD. Leptomeningial and parenchymal vessels showed extensive deposition of $A \beta$ amyloid protein. Numerous senile plaques consisted of large $A \beta$ amyloid cores, often measuring more than $30 \mu \mathrm{m}$ in diameter and were surrounded by a fine meshwork of dystrophic neurites. In addition, there were a large number of paired helical filaments in pyramidal neurons and dystrophic neurites. Our findings show that the APP692 mutation leads to morphological abnormalities that are similar to $\mathrm{AD}$, but the morphology of senile plaques is clearly
\end{abstract}

P. Cras (两) · C. Ceuterick · J. J. Martin

Laboratory of Neuropathology, Born-Bunge Foundation,

University of Antwerp, Universiteitsplein 1 ,

B-2610 Wilrijk, Belgium

e-mail; cras@uia.ua.ac.be,

Tel.: 32-3-820-2604, Fax: 32-3-820-2248

L. Hendriks · C. Van Broeckhoven

Laboratory of Neurogenetics,

Flanders Interuniversity Institute of Biotechnology (VIB),

Born Bunge Foundation, Department of Biochemistry,

University of Antwerp, Wilrijk, Belgium

S. Z. Stefanko · J. M. Kros

Department of Pathology, Erasmus University,

Rotterdam, The Netherlands

F. van Harskamp

Department of Neurology, Erasmus University,

Rotterdam, The Netherlands

F. van Harskamp · C. M. van Duijn · A. Hofman Department of Epidemiology and Biostatistics,

Erasmus University, Rotterdam, The Netherlands distinct from that described in sporadic and chromosome 14-linked AD patients, in patients with APP717 mutations causing familial, presenile $\mathrm{AD}$ and in patients with the APP693 mutation causing HCHWA-D.

Key words Congophilic angiopathy · Amyloid precursor protein $\cdot$ Dementia $\cdot$ Neurofibrillary tangles $\cdot$ Tau

\section{Introduction}

Alzheimer's disease (AD) is a progressive dementia that is characterized by the presence of neurofibrillary tangles and by $A \beta$ amyloid deposits in senile plaques (SP) and vessel walls. These $A \beta$ amyloid deposits are associated with dystrophic neurites that show an accumulation of abnormally phosphorylated tau [2]. The A $\beta$ amyloid in SP is derived from a larger amyloid precursor protein (APP), the gene of which is located on chromosome 21 [12]. Mutations at codons 717 and 670/671 of the APP gene have been identified in familial early onset $\mathrm{AD}[5,9,23,24]$. APP mutations have been reported as rare genetic causes of presenile familial AD [30]. Most patients with APP mutations show a morphological picture that highly resembles sporadic AD, although the severity of the morphological changes is usually impressive [8, 13, 14, 19]. In one single family, a patient showed cortical Lewy bodies in addition to neurofibrillary tangles (NFT) [16], while another showed a typical morphological picture of AD [4]. In hereditary cerebral hemorrhage with amyloidosis of the Dutch type (HCHWA-D) an APP mutation was identified at codon 693 replacing a glutamine for glutamic acid [17, 31]. In HCHWA-D, the neuropathological changes are dominated by the presence of an extensive congophilic amyloid angiopathy (CAA) [18]. SP are present in moderate numbers and are mostly of the diffuse or preamyloid type [29]. Dystrophic, ubiquitin (Ub)-immunoreactive neurites have been demostrated in the corona of senile plaques and in the parenchyma surrounding amyloidotic vessels, but are free from paired helical filaments (PHF) [27]. In sporadic forms of CAA, Ub-immunoreactive and tau-negative neurites have also been observed 
[26]. In fact, the absence of abnormally phosphorylated tau may be the reason why dystrophic neurites have not consistently been reported in HCHWA-D. We have reported a APP mutation at codon 692 replacing a Gly for Ala [11]. In this Dutch family, also called family 1302, the clinical history is characterized by a progressive dementia indistinguishable from $\mathrm{AD}$ in some and intracerebral hemorrhages in other patients. At the time our first report, only a single biopsy sample was available, of patient IV3 , a 42-year-old woman who had suffered an intracerebral hemorrhage. In this biopsy specimen CAA was very prominent, although numerous senile plaques were also detected,with APP- and Ub-immunoreactive dystrophic neurites. At the time of the hemorrhage, the patients' cognitive status was unimpaired and no NFT were observed. Since then, she has developed a progressive dementia [33]. Since our first report, two patients of this family have died after suffering a progressive dementia, and brain autopsy was performed in both. The clinical findings in family 1302 will be reported separately (van Harskamp et al., in preparation). The present report concerns the neuropathological study of patients IV-6 and IV-2. Our morphological findings support the diagnosis of AD in both patients. Furthermore, this report describes the neuropathological abnormalities, which are remarkable for the large amyloid core SP, the presence of NFT and an extensive amyloid angiopathy.

\section{Materials and methods}

\section{Patients}

Case 1

The patient was 48 years old when she first came to medical attention (individual IV-6 [11, 33]). She complained of increasing memory difficulties over a 2-year period, but was nevertheless able to manage her household and drive a car. Mental state examination showed slight disorientation and she appeared to confabulate. A CT scan of the brain was performed and showed no abnormalities. She developed a progressive dementia together with signs of a hypokinetic extrapyramidal syndrome. She was treated for a depression with vital signs. Four years after the onset of her dementia, she was admitted to a nursing home, where she died of pneumonia at the age of 55. A diagnosis of probable AD was made according to NINCDS-ADRDA criteria [21].

\section{Case 2}

Patient IV-2 was a man who showed memory disturbances at age 49. He complained of frequent headaches and showed behavioral disturbances. He subsequently showed language difficulties, construction apraxia and dyscalculia. He died of pneumonia at the age of 57 years.

\section{Histopathology}

After fixation in $4 \%$ formaldehyde, the brains were cut into frontal sections which were examined macroscopically and photographed. Large cryosections were stained with the following techniques: Spielmeyer for myelin sheaths, Holzer for fibrillar glia, cresyl violet stain for Nissl bodies, Sudan III for lipid breakdown products and periodic acid-Schiff for sugar residues. Paraffin blocks were stained with cresyl violet, hematoxylin eosin, Bodian, periodic acid-Schiff and with various mono- and polyclonal antibodies to:
(1) A $\beta$ amyloid 4G8 (courtesy of H. Wisniewski) [35]; (2) APP (22C11, Boehringer) [34]; (3) abnormally phosphorylated tau Ser 202 (AT8, Innogenetics) [22]; (4) glial fibrillary acidic protein (GFAP; Dako); (5) ubiquitin (Novocastra and Dako); (6) microglia (HLA-DR, TAL1B5) (Dako), F14 [6] and CD68 (Dako); (7) phosphorylated neurofilaments [22]; and (8) prion protein (3F4, Senetek).

Tissue fragments of the cerebellum superior frontal and temporal gyri, area striata and hippocampus were also fixed or post-fixed in glutaraldehyde followed by osmium tetroxide and embedded in Araldite for electron microscopy.

Morphometric analysis was performed by digitizing images with a Sony camera mounted on a Reichert Polyvar microscope. The images were acquired with a Mass Microsystems frame grabber and processed with a Macintosh fx computer. Measurements were performed with the public domain program Image version 1.35 (courtesy of Wayne Rassband, NIH, Bethesda, Md.). The amyloid core size of SP in the patients with the APP692 mutation was compared with the SP observed in one sporadic, late onset $\mathrm{AD}$ and three early onset familial AD patients with a presenilin-1 mutation $[7,20]$. A total of 140 SP were measured.

\section{Results}

\section{Patient IV-2}

Macroscopic examination showed moderate cortical atrophy that predominated in the frontal lobes. The meninges

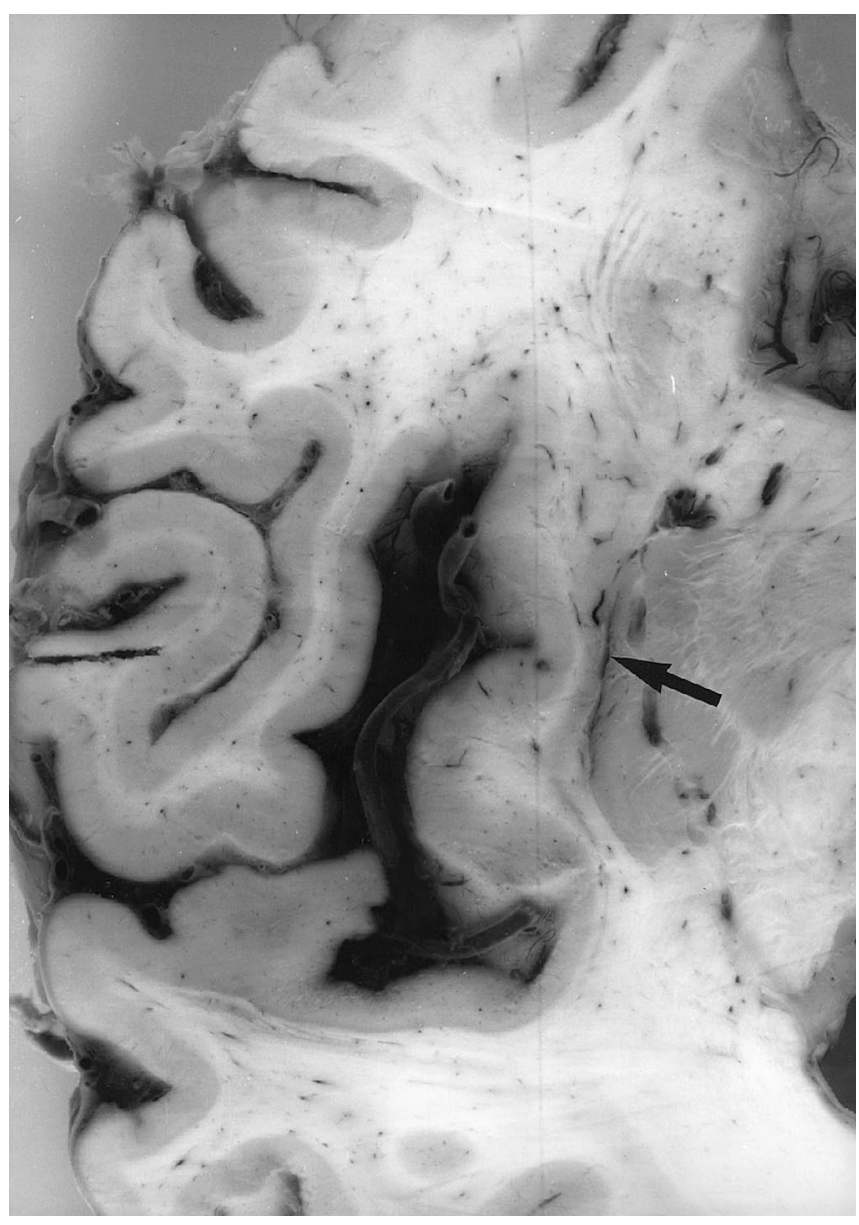

Fig. 1 Small subcortical hemorrhage in the right insular region (arrow) 


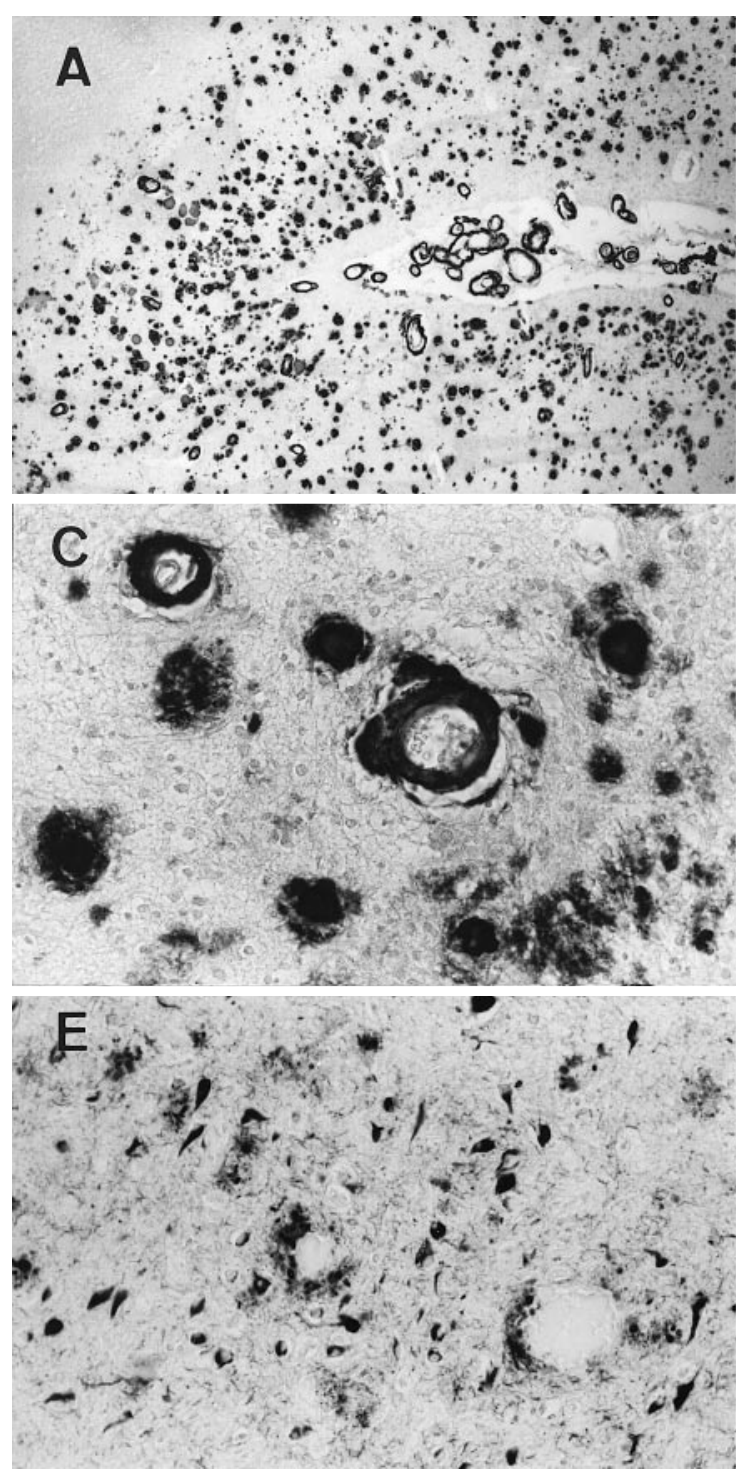

Fig. 2 A Numerous amyloid deposits and congophilic angiopathy in the neocortex (antibody $4 \mathrm{G} 8$ directed to $A \beta$ amyloid). B Neurofibrillary tangles are abundant in all neocortical locations. Detail of the superior temporal gyrus (immunostained with AT8, an antibody directed to phosphorylated serine 202 of the microtubule-associated protein tau. C Amyloid deposition in arterioles and dysoric angiopathy (4G8). D Typical large amyloid core senile plaques (4G8). E Large amyloid core senile plaques are surrounded by a thin rim of dystrophic neurites (AT8). F Large amyloid core containing senile plaques in the Purkinje cell layer of the cerebellum (Nissl stain). A $\times 18 ; \mathbf{B} \times 53 ; \mathbf{C}, \mathbf{D}, \mathbf{F} \times 144 ; \mathbf{E} \times 93$

of the frontal and temporal lobes were thickened and showed brown discoloration. In the cortex and subcortical white matter, there were small cavities, which were often surrounded by a brownish hue (Fig. 1). Similar foci were found in the right putamen and the cerebellum.

The superior frontal, superior temporal gyri and the area striata showed numerous leptomeningial vessels with amyloid deposits. Numerous hemosiderin-laden macrophages were also found in the leptomeninges. The underlying cortex showed moderate neuronal loss, superficial
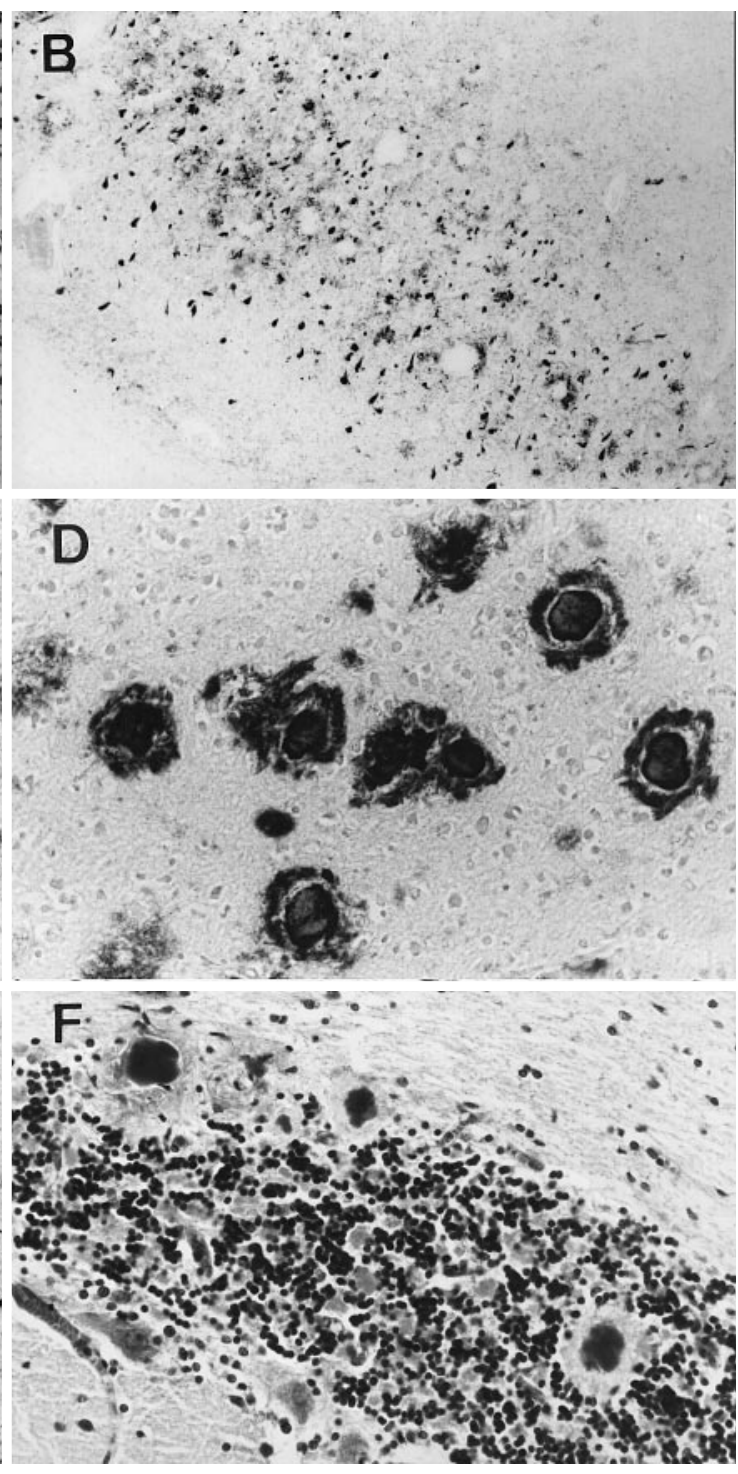

layer microspongiosis and reactive gliosis. In deeper cortical layers, spongiosis was less pronounced, but there were some expanded perivascular spaces. SP of different types were present throughout the whole cortex. Large amyloid core, as well as neuritic and diffuse-type SP were observed. Amyloid deposits were also observed in arterioles and capillaries. Some of these capillaries showed amyloid encroaching on the lumen, which was sometimes highly reduced in caliber. Neurofibrillary changes were more numerous in the superior temporal gyrus than in the other cortical locations. Spongiosis was most pronounced in the occipital area, where it also occurred in the white matter. In the entorhinal cortex, there was only mild neuronal loss in layer II. Some of the pyramidal neurons contained NFT. There were numerous diffuse and neuritic SP in the same region. The subiculum showed moderate neuronal loss, numerous NFT and SP. In areas CA1 and CA2 there was intense neuronal loss. In contrast, areas CA3 and CA4 were relatively spared. Immunohistochemistry showed numerous 4G8 (A $\beta$ )-immunoreactive amyloid deposits. Dystrophic neurites and NFT were immunoreac- 
tive with AT8, which also revealed numerous neuropil threads. The inferior temporal gyrus contained numerous NFT in pyramidal neurons. Microglia was intensely decorated by antibodies to HLA-DR and CD68, while the reactive astrocytes were GFAP immunoreactive. Less numerous microglial cells were immunostained with F14.

Subcortical structures showed fewer abnormalities. There were some SP in the nucleus caudatus, putamen and pallidum. The basal nucleus of Meynert showed mild neuronal loss and numerous SP. The putamen and right frontal subcortical white matter showed small cavities with rarefaction of myelin sheaths and numerous hemosiderin-laden macrophages. The thalamus showed a moderate number of SP, mostly in the formatio medialis and nucleus ventralis oralis.

The cerebellum showed moderate loss of Purkinje cells, thinning and spongiosis of the molecular layer. The dentate nucleus was normal. In the mesencephalon, some SP were found in the periaqueductal gray matter. The pons showed neuronal loss in the locus ceruleus and nucleus raphe dorsalis. Some remaining neurons contained globose-type NFT. Cervical and dorsal spinal cord were normal.

\section{Patient IV-6}

General autopsy showed bilateral bronchopneumonia. The brain weighed $970 \mathrm{~g}$ and the substantia nigra was pale. Gross examination of the brain showed frontal and temporal cortical atrophy and compensatory widening of the lateral ventricles. Microscopic examination showed diffuse cortical atrophy with severe neuronal cell loss, diffuse microspongiosis of the upper cortical layers and astrocytic gliosis. Lewy bodies were present in some substantia nigra neurons, but no cortical Lewy bodies were found in the limbic cortex or in the substantia innominata. Using cresyl violet staining, the walls of numerous blood vessels were seen to be thickened by metachromatic deposits. Large numbers of SP were observed in all isocortical gyri, the parahippocampal gyrus, amygdaloid nucleus, and hippocampus, while fewer were found in the neostriatum, thalamus, mesencephalic tectum and cerebellar cortex (Fig.2). Many cerebral cortical plaques were only constituted of a large amyloid core, while others were surrounded by a meshwork of dystrophic neurites. The amyloid deposits were intensely stained by the monoclonal 4G8 immunoreactive with $A \beta$ (Fig. 2) and less intensely and less frequently with the monoclonal antibody to APP (22C11) (not shown). Numerous small vessels and capillaries showed accumulation of $\mathrm{A} \beta$ amyloid in the basement membrane. Amyloid in the cortical and leptomeningeal vessel walls was immunostained by the 4G8 antibody. In the cerebellar cortex, SP were found in all cortical layers.

These SP usually consisted of a large amyloid core without a disturbance of the surrounding parenchyma (Fig. 2). Their structure resembled kuru-type plaques, but they were definitely larger in size. In areas CA1 and CA2

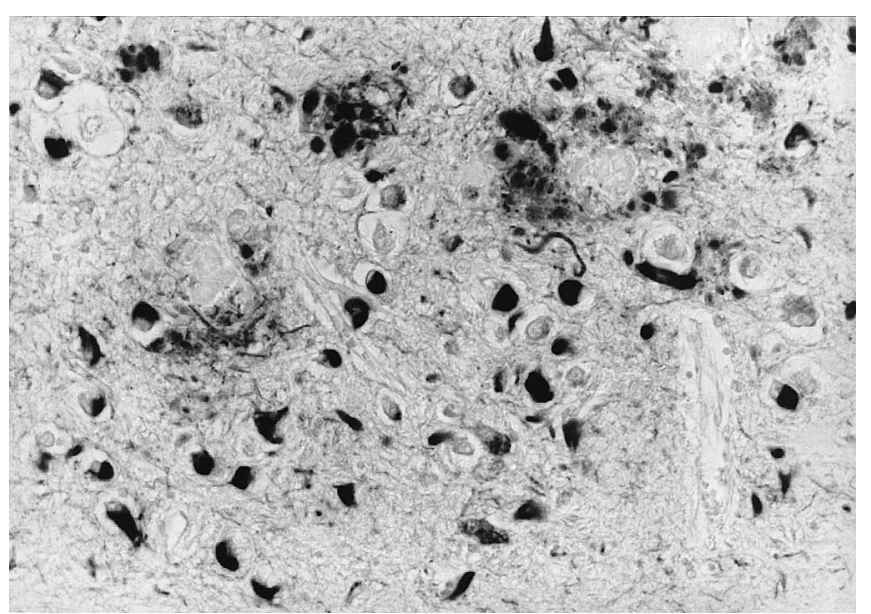

Fig. 3 Numerous neurofibrillary tangles and dystrophic neurites are immunostained by the monoclonal antibody AT8. $\times 245$

of the hippocampus, there was intense neuronal loss, while in areas CA3 and CA4 neuronal loss was less pronounced. NFT were present in large numbers as shown with the AT8 antibody immunolabelling abnormally phosphorylated protein tau (Fig.3). Extracellular NFT were extremely rare. Ub immunoreactivity was found in the cytoplasm of neurons and was only associated with NFT. No Lewy bodies could be demonstrated. Numerous astrocytes and microglia were present around the SP as shown by their GFAP and HLA-DR immunoreactivity, respectively (not shown).

Immunocytochemistry for prion protein using the hydrated autoclave technique and monoclonal antibody $3 \mathrm{~F} 4$ was negative (not shown).

\section{Morphometry}

Two features of these large amyloid core SP were remarkable. First, they constituted the majority of the SP. Second, the size of the amyloid core as compared to the total diameter of the SP was exceedingly large (Figs.4, 5). We

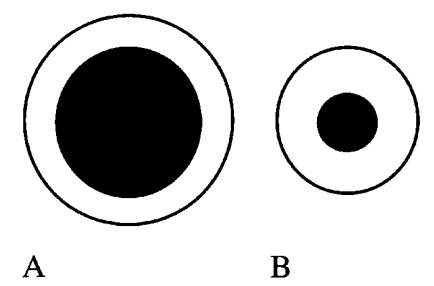

Fig. 4 A, B Comparison of average amyloid core and total plaque size in the APP692 mutation and in AD. A The average diameter of amyloid core containing senile plaques in the APP692 mutation is $32 \mu \mathrm{m}$, while the plaque core accounts for $48 \%$ of the plaque. B In contrast, similar plaques in chromosome 14-linked and sporadic AD patients measure on average $22 \mu \mathrm{m}$, while the core accounts for $16 \%$ of the total plaque size (based on measurements of 140 amyloid core containing senile plaques in $4 \mathrm{AD}$ patients) ( $A D \mathrm{Alz}-$ heimer's disease) 
Fig. 5 Size histogram of the senile plaque cores in the APP692 mutation patients (APP692) as compared to sporadic and chromosome 14linked AD patients $(\mathrm{C})$

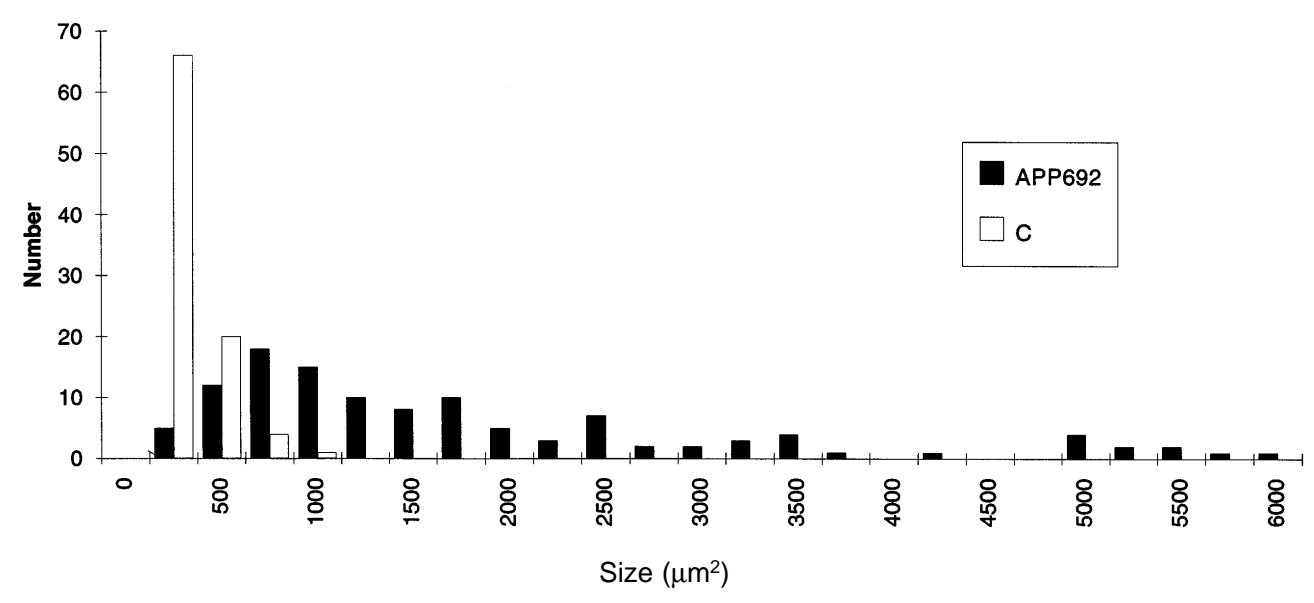

compared the ratio of the area of the amyloid core to that of the total SP, both in the patients with the APP692 mutation and in sporadic and familial AD cases. We found that the amyloid core in the APP692 mutation comprised on average $48 \pm 17 \%$ of the total plaque, while the amyloid core in sporadic and chromosome 14-linked familial AD SP comprised on average only $16 \pm 12 \%$ of the total plaque size (Fig. 4). The corona of amyloid core containing SP was small in comparison to the size of the core.

\section{Electron microscopy}

Electron microscopy on samples of the amygdaloid nucleus, frontal, temporal and occipital cortices showed typical PHF in the neuronal perikarya. SP were mainly constituted of large cores of amyloid deposits grouped in bundles and with a radial distribution (Fig. 6 A). The amyloid core size often exceeded $30 \mu \mathrm{m}$. These large amyloid cores existed in the neuropil or close to small blood vessels. Microglial cells with debris including amyloid filaments and lipofuscin bodies were often found in the neighborhood of amyloid deposits. The vessel walls were thickened and contained numerous amyloid filaments (Fig. 6B). In some vessels, the amyloid was not confined to the vessel wall, but infiltrated the surrounding brain parenchyma. Associated with the basement membranes of some capillaries were large masses of amyloid, sometimes measuring $50 \mu \mathrm{m}$ in diameter. In the hippocampus, neurons often contained PHF. Ghost tangles were associated with amyloid deposits, glial filaments and dystrophic neurites. Granulovacuolar degeneration and a few Hirano bodies were also found in hippocampal neurons. Large core amyloid plaques were often surrounded by astrocytes or microglia.

The cerebellum showed fewer abnormalities. The Purkinje cells were normal, but in the same layer, we observed numerous large core amyloid SP, of which the diameter ranged between 6 and $35 \mu \mathrm{m}$. Intermingled among the amyloid fibrils were astrocytic extensions filled with intermediate filaments. Furthermore, dystrophic neurites were present, with numerous vesicles and amorphous dense structures, but no PHF. Very large perivascular
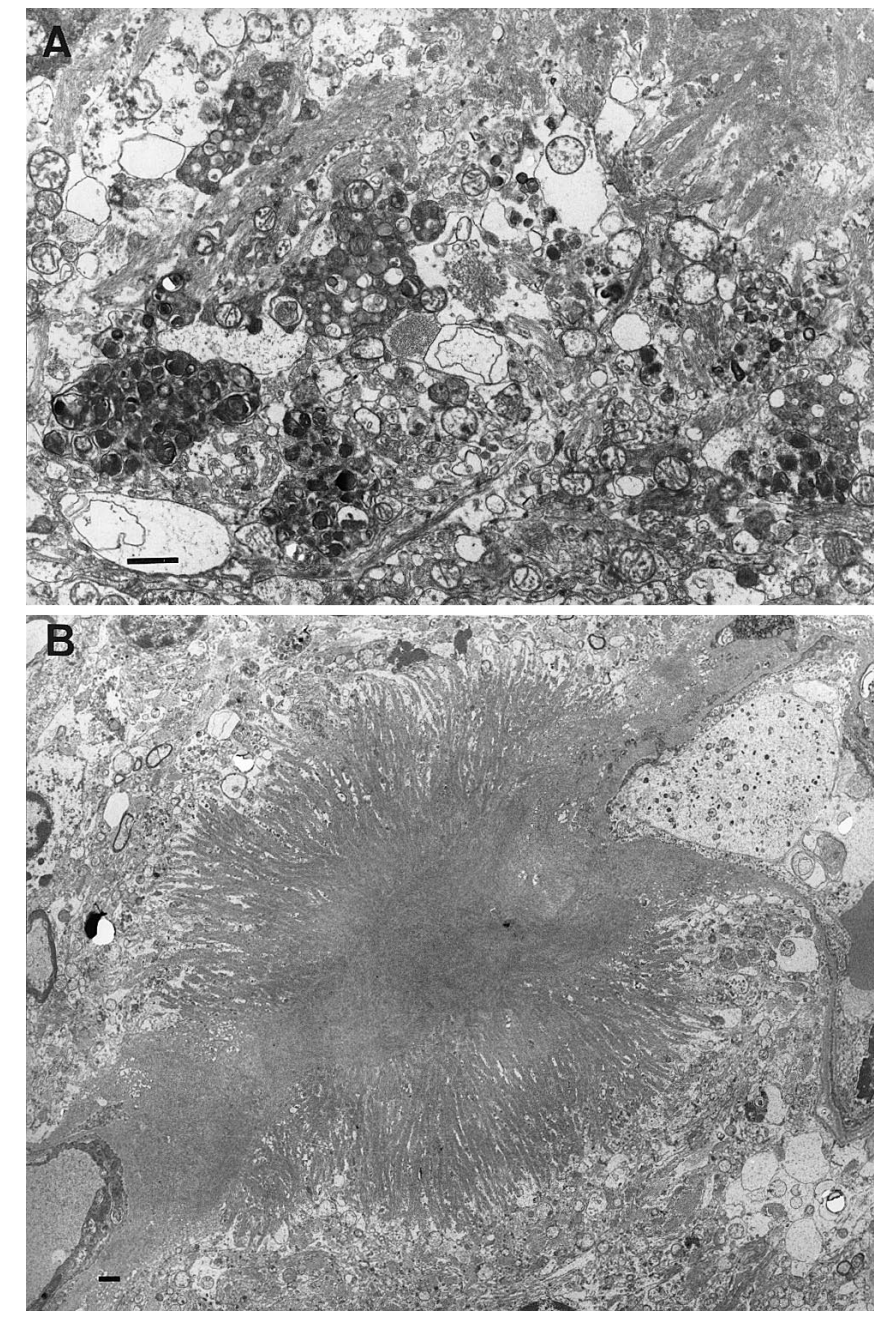

Fig. 6 A Electron micrograph of the periphery of a senile plaque showing amyloid fibrils surrounded by dystrophic neurites in the frontal cortex. B Electron micrograph of a large dysoric amyloid deposit which spread radially from a vessel wall to the surrounding neuropil in the cerebellar cortex. Sections were fixed in glutaraldehyde, followed by postfixation in osmium tetroxide, embedding in Epon, and staining with uranyl acetate and lead citrate. Bars A, B $1 \mu \mathrm{m}$ 
Table 1 Essential differences of clinical events and neuropathological changes in APP692 mutation, hereditary cerebral hemorrhage with amyloidosis $(H C H W A-D)$ and Alzheimer's disease $(A D)(S P$ senile plaque)

\begin{tabular}{llll}
\hline & APP692 & HCHWA-D & AD \\
\hline Amyloid angiopathy & ++++ & ++++ & ++ \\
Number of senile plaques & ++++ & ++ & ++++ \\
Diffuse-type SP & Associated with capillaries & Predominate & Variable \\
Cerebellar SP & Large amyloid core & $?$ & Mostly diffuse \\
Neurofibrillary tangles & Intracellular & Rare & Intra- and extracellular \\
Tau-immunoreactive & ++++ & - & ++++ \\
$\quad$ dystrophic neurites & & & \\
Dementia & Progressive & Vascular type & Progressive \\
Intracerebral hemorrhage & Frequent & Characteristic & Rare \\
\hline
\end{tabular}

amyloid depositions were also found associated with the basement membrane. Immediately surrounding amyloidotic capillaries were dystrophic neurites.

\section{Discussion}

We describe the neuropathological examination of the brains of two patients of family 1302: a 55-year-old woman and a 57-year-old man carrying the APP A692G mutation who were diagnosed with probable AD according to NINCDS-ADRDA criteria. Examination of the brains showed lesions that fulfilled the neuropathological criteria for $\mathrm{AD}$ [15]. Cortical and subcortical neuronal loss was accompanied by the presence of numerous SP and congophilic angiopathy. However, the SP of the patients we report were clearly different from these found in classical AD, large core amyloid plaques being observed throughout the neocortex and cerebellum. In addition, there was very extensive amyloid angiopathy with large amyloid masses encroaching on the lumen of capillaries. Neuronal cell loss and the presence of Lewy bodies in the substantia nigra in patient IV-6 were probably related to her extrapyramidal symptoms. As there were no cortical Lewy bodies, it is likely that she suffered from coexistent Parkinson's disease, rather than diffuse Lewy body disease or the diffuse Lewy body variant of AD.

AD patients show a progressive dementia that is correlated with an increase in the number of SP, NFT and synapse loss found at autopsy [28]. Most patients with HCHWA-D show a vascular-type dementia that is correlated with the number of lesions observed on CT scan of the brain, although a few patients also show progressive dementia in the absence of intracerebral hemorrhage [3, $10,32]$. Amyloid deposits are also found in normal aging, especially in the medial temporal lobes, and in HCHWA$\mathrm{D}$, in the absence of dementia. In a biopsy specimen from the hemorrhagic stroke patient IV-3 carrying the APP692 mutation that we examined previously [11], we observed numerous SP and extensive CAA, but no NFT. At the time of the biopsy, this patient was cognitively intact, but since then, she has developed a progressive dementia fulfilling the criteria for probable AD [33].

The differences between the neuropathological abnormalities of early onset AD caused by the APP717 mutation, APP693 causing HCHWA-D, and the presently de- scribed patient with the APP692 mutation relate not only to the different phenotypes of amyloid deposits, but also to neurofibrillary pathology. In the patients we described in this report, a specific type of SP is associated with AD changes consisting of NFT, neuropil threads and neuritic plaques with dystrophic neurites containing abnormally phosphorylated tau. Therefore, it seems likely that the presenile dementia in this patient is related more to the presence of NFT and neuritic changes, than to the presence of amyloid deposits, which is sustained by the cognitive intactness in patient IV-3. The essential differences of clinical events and neuropathological changes in APP692 mutation, HCHWA-D and AD are shown in Table 1.

The pathogensis of $A \beta$ amyloid deposits in SP and CAA and their relationship with NFT in AD is still a matter of considerable debate. Microglia, astrocytes, neurons and smooth muscle cells alike could be involved in the production and metabolism of APP leading to A $\beta$ amyloid deposits $[1,25,36]$. While in AD, the APP717 mutation leads to the development of numerous NFT, these are strikingly absent from the brains of patients with the APP693 mutation in HCHWA-D. In contrast, in the APP692 mutation, extensive CAA is associated with the presence of numerous NFT.

The site of the APP mutation apparently determines the location of $A \beta$ amyloid deposition in cortex or vessel walls. The predominant type of $A \beta$ amyloid that is deposited, be it $A \beta 1-40$ or $A \beta 1-42(43)$, may also be influenced by the presence and site of mutations. Lastly, APP mutations and their site could, either directly or indirectly, play a role in the susceptibility of neurons to develop NFT. This last hypothesis should be further examined in mutant APP transfected neuronal cell lines or transgenic animals.

Acknowledgements The expert collaboration of U. Lübke, I. Bats and J. Van Bracht is gratefully acknowledged. This work was supported by FGWO grant no. 3.0020.94, by the NFWO and the Flemish Biotechnology Program (CT93-0015 and CT96-0554 and BIOTECH (CT94-2065 and CT96), BIOMED chromosome 21, Interuniversity Attraction Poles IUAP-P4/17, Commission of the European Community BIOMED BMM4-CT96-0554 and BIOTECH CT96-0743 and the Focused Giving Program-Johnson \& Johnson. 


\section{References}

1. Allsop D, Haga S-I, Haga C, Ikeda S-I, Mann DMA, Ishii T (1989) Early senile plaques in Down's syndrome brains show a close relationship with cell bodies of neurons. Neuropathol Appl Neurobiol 15:531-542

2. Barcikowska M, Wisniewski HM, Bancher C, Grundke-Iqbal I (1989) About the presence of paired helical filaments in dystrophic neurites participating in the plaque formation. Acta Neuropathol $78: 225-231$

3. Bornebroek M, Haan J, Maat-Schieman ML, van Duijnen SG, Roos R (1996) Hereditary cerebral hemorrhage with amyloidosis-Dutch type: review of clinical, radiologic and genetic aspects. Brain Pathol 6:111-114

4. Cairns NJ, Chadwick A, Lantos PL, Levy R, Rossor MN (1993) BetaA4 protein deposition in familial alzheimer's disease with the mutation in codon 717 of the betaA4 amyloid precursor protein gene and sporadic alzheimer's disease. Neurosci Lett 149:137-140

5. Chartierharlin MC, Crawford F, Hamandi K, Mullan M, Goate A, Hardy J, Backhovens H, Martin JJ, Van Broeckhoven C (1991) Screening for the beta-amyloid precursor protein mutation (APP717-Val $\rightarrow$ Ile) in extended pedigrees with early onset Alzheimer's disease. Neurosci Lett 129:134-135

6. Cras P, Gheuens J, Lubke U, Boons J, Vandermeeren M, Van HH, Martin JJ (1990) A monoclonal antibody raised against Alzheimer cortex that specifically recognizes a subpopulation of microglial cells. J Histochem Cytochem 38: 1201-1207

7. Cruts M, Backhovens H, Theuns J, Clark RF, Lepaslier D, Weissenbach J, Goate AM, Martin JJ, Van Broeckhoven C (1995) Genetic and physical characterization of the early-onset alzheimer's disease AD3 locus on chromosome 14q24.3. Hum Mol Genet 4:1355-1364

8. Farlow M, Murrell J, Ghetti B, Unverzagt F, Zeldenrust S, Benson M (1994) Clinical characteristics in a kindred with early-onset Alzheimer's disease and their linkage to a G to T change at position 2149 of the amyloid precursor protein gene. Neurology $44: 105-111$

9. Goate A, Chartierharlin MC, Mullan M, Brown J, Crawford F, Fidani L, Giuffra L, Haynes A, Irving N, James L, Mant R, Newton P, Rooke K, Roques P, Talbot C, Pericak-Vance M, Roses A, Williamson R, Rossor M, Owen M, Hardy J (1991) Segregation of a missense mutation in the amyloid precursor protein gene with familial Alzheimer's disease. Nature 349: 704-706

10. Haan J, Algra PR, Roos RA (1990) Hereditary cerebral hemorrhage with amyloidosis-Dutch type. Clinical and computed tomographic analysis of 24 cases. Arch Neurol 47:649-653

11. Hendriks L, Van Duijn CM, Cras P, Cruts M, Van Hul W, Harskamp Fv, Warren A, McInnis MG, Antonarakis SE, Martin J-J, Hofman A, Van Broeckhoven C (1992) Presenile dementia and cerebral hemorrhage linked to a mutation at codon 692 of the $\beta$-amyloid precursor protein gene. Nat Genet 1 : 218-221

12. Kang J, Lemaire H-G, Unterbeck A, Salbaum JM, Masters CL, Grzeschik K-H, Multhaup G, Beyreuther K, Muller-Hill B (1987) The precursor of Alzheimer's disease amyloid A4 protein resembles a cell-surface receptor. Nature 325:733-736

13. Karlinsky H, Vaula G, Haines JL, Ridgley J, Bergeron C, Mortilla M, Tupler RG, Percy ME, Robitaille Y, Noldy NE, Yip TCK, Tanzi RE, Gusella JF, Becker R, Berg JM, McLachlan DRC, ST George-Hyslop PH (1992) Molecular and prospective phenotypic characterization of a pedigree with familial Alzheimer's disease and a missense mutation in codon 717 of the $\beta$-amyloid precursor protein gene. Neurology 42: 1445-1453

14. Kennedy AM, Newman S, McCaddon A, Ball J, Roques P, Mullan M, Hardy J, Chartier-Harlin MC, Frackowiak RSJ, Warrington EK, Rossor MN (1993) Familial Alzheimer's disease. A pedigree with a mis-sense mutation in the amyloid precursor protein gene (amyloid precursor protein 717 valine $\rightarrow$ glycine). Brain 116:309-324
15. Khatchaturian ZS (1985) Diagnosis of Alzheimer disease. Arch Neurol 42: 1097-1105

16. Lantos PL, Ovenstone IM, Johnson J, Clelland CA, Roques P, Rossor MN (1994) Lewy bodies in the brain of two members of a family with the 717 (Val to Ile) mutation of the amyloid precursor protein gene. Neurosci Lett 172:77-79

17. Levy E, Carman MD, Fernandez MI, Power MD, Lieberburg I, Van Duijnen SG, Bots GT, Luyendijk W, Frangione B (1990) Mutation of the Alzheimer's disease amyloid gene in hereditary cerebral hemorrhage, Dutch type. Science 248:1124-1126 18. Maat-Schieman ML, Van Duijnen SG, Bornebroek M, Haan J, Roos R (1996) Hereditary cerebral hemorrhage with amyloidosis-Dutch type: review of histopathological aspects. Brain Pathol 6:115-120

19. Mann DMA, Jones D, Snowden JS, Neary D, Hardy J (1992) Pathological changes in the brain of a patient with familial Alzheimer's disease having a missense mutation at codon-717 in the amyloid precursor protein gene. Neurosci Lett 137: 225-228

20. Martin JJ, Gheuens J, Bruyland M, Cras P, Vandenberghe A, Masters CL, Beyreuther K, Dom R, Ceuterick C, Lubke U, Vanheuverswijn H, Dewinter G, Van Broeckhoven C (1991) Early-onset Alzheimer's disease in two large Belgian families. Neurology $41: 62-68$

21. McKhann G, Drachman D, Folstein M, Katzman R, Price D, Stadman E (1984) Clinical diagnosis of Alzheimer's disease: report of the NINCDS-ADRDA Work Group under the auspices of the Department of Health and Human Services Task Force on Alzheimer's disease. Neurology 34:939

22. Mercken M, Vandermeeren M, Lübke U, Six J, Boons J, Van de Voorde A, Martin JJ, Gheuens J (1992) Monoclonal antibodies with selective specificity of Alzheimer tau are directed against phosphatase-sensitive epitopes. Acta Neuropathol 84: 265-272

23. Mullan M, Tsuji S, Miki T, et al (1993) Clinical comparison of Alzheimer's disease in pedigrees with the codon $717 \mathrm{Val} \rightarrow$ Ile mutation in the amyloid precursor protein gene. Neurobiol Aging 14:407-419

24. Murrell J, Farlow M, Ghetti B, Benson MD (1991) A mutation in the amyloid precursor protein associated with hereditary Alzheimer's disease. Science 254:97-99

25. Siman R, Card JP, Nelson RB, Davis LG (1989) Expression of beta-amyloid precursor protein in reactive astrocytes following neuronal damage. Neuron 3:275-285

26. Tabaton M, Cammarata S, Mandybur T, Richey P, Kawai M, Perry G, Gambetti P (1992) Senile plaques in cerebral amyloid angiopathy show accumulation of amyoid precursor protein without cytoskeletal abnormalities. Brain Res 593:299-303

27. Tagliavini F, Giaccone G, Bugiani O, Frangione B (1993) Ubiquitinated neurites are associated with preamyloid and cerebral amyloid-beta deposits in patients with hereditary cerebral hemorrhage with amyloidosis dutch type. Acta Neuropathol $85: 267-271$

28. Terry RD, Masliah E, Salmon DP, Butters N, Deteresa R, Hill R, Hansan LA, Katzman R (1991) Physical basis of cognitive alterations in Alzheimer's disease - Synapse loss is the major correlate of cognitive impairment. Ann Neurol 30:572-580

29. Timmers WF, Tagliavini F, Haan J, Frangione B (1990) Parenchymal preamyloid and amyloid deposits in the brains of patients with hereditary cerebral hemorrhage with amyloidosisDutch type. Neurosci Lett $118: 223-226$

30. Van Broeckhoven C (1995) Molecular genetics of Alzheimer's disease. Eur Neurol 35:8-19

31. Van Broeckhoven C, Haan J, Bakker E, Hardy JA, Van Hul W, Wehnert A, Vegter Van der Vlis M, Roos RA (1990) Amyloid beta protein precursor gene and hereditary cerebral hemorrhage with amyloidosis (Dutch). Science 248:1120-1122

32. Van Duijnen SG, Castano EM, Prelli F, Bots GT, Luyendijk W, Frangione B (1987) Hereditary cerebral hemorrhage with amyloidosis in patients of Dutch origin is related to Alzheimer disease. Proc Natl Acad Sci USA 84:5991-5994 
33. Van Harskamp F, Cras P, Hendriks L, Kros M, Martin JJ, Hofman A, Van Broeckhoven C, Van Duijn CM (1997) A family with early-onset Alzheimer's disease and cerebral hemorrhage due to a mutation in the $\beta$-amyloid precursor protein. In: Iqbal K, Nishimura T, Takeda M, Wisniewski H (eds) Alzheimer's disease: biology, diagnosis and therapeutics. Wiley, New York, pp 155-159

34. Weidemann A, Konig G, Bunke D, Fischer P, Salbaum JM, Masters CL, Beyreuther K (1989) Identification, biogenesis, and localization of precursors of Alzheimer's disease A4 amyloid protein. Cell 57:115-126
35. Wisniewski HM, Bancher C, Barcikowska M, Wen GY, Currie J (1989) Spectrum of morphological appearances of amyloid deposits in Alzheimer's disease. Acta Neuropathol 78:337347

36. Wisniewski HM, Wegiel J, Wang KC, Lach B (1992) Ultrastructural studies of the cells forming amyloid in the cortical vessel wall in Alzheimer's disease. Acta Neuropathol 84:117127 